\title{
Imunogenicidade de isolados de herpesvírus bovino 5 como candidatos à vacina
}

\author{
Immunogenicity of bovine herpesvirus 5 isolates as vaccine candidates
}

\author{
Luiz Felipe Lourenço de Souza ${ }^{I}$ Abelardo Silva Júnior ${ }^{I}$ Carla Maria Batista de Freitas ${ }^{\text {II }}$ \\ Ethel Cardoso de Freitas ${ }^{\mathrm{II}}$ Eduardo Furtado Flores ${ }^{\mathrm{III}}$ Márcia Rogéria de Almeida ${ }^{{ }^{*}}$ \\ Mauro Pires Moraes ${ }^{\mathrm{IV}}$
}

RESUMO

O herpesvírus bovino 5 (BoHV-5) é o agente da menigoencefalite herpética bovina. A doença neurológica, associada à infecção pelo BoHV-5, apresenta altas taxas de letalidade em bovinos jovens e está disseminada no Brasil. A prevenção das perdas causadas pela infecção pelo herpesvírus está baseada, principalmente, na imunização dos animais. Nesse sentido, foi delineada uma comparação entre isolados de BoHV-5, buscando selecionar o isolado mais antigênico para a formulação de vacinas. As formulações inativadas foram produzidas com os isolados ISO9898292, SV507, SV163, 1807 e EVI145 e administradas a cinco grupos de 10 ovelhas cada, que receberam duas doses vacinais por via intramuscular com intervalo de 21 dias. Foram realizadas coletas de sangue para análise de presença de anticorpos por soroneutralização e acompanhamento dos animais até o 63o dia após a primo-vacinação. Foram observados dois picos na curva de anticorpos, o primeiro no dia 14, após a vacinação, quando os títulos médios de anticorpos variaram entre 23,1 e 138,6. O segundo pico foi observado 14 dias após a revacinação, quando os títulos médios variaram entre 301,3 e 1017,5. No 42 dia após a revacinação, foi observada variação de título entre 82,4 e 305,9. A diferença entre as médias de títulos de anticorpos de cada grupo de animais sugere uma menor antigenicidade do isolado ISO9898292 em relação aos demais, demonstrando uma possível variação antigênica entre os isolados. Todos os isolados, com exceção do ISO9898292, mostraram-se imunogênicos para a indução de anticorpos.

Palavras-chave: herpesvírus bovino 5, meningoencefalite bovina, soroneutralização, vacinas.

\begin{abstract}
Herpesvirus bovine 5 (BoHV-5) is the agent of bovine herpetic menigoencephalitis. The neurological disease associated with the infection is highly lethal in young cattle and it is widespread in Brazil. Control of the clinical signs caused by herpesviruses is based mainly on the immunization of cattle. A comparative study was performed among Brazilian $\mathrm{BoHV}-5$ isolates to select the more antigenic virus. Inactivated vaccines were formulated using isolates ISO9898292, SV507, SV163, 1807 and EVI145 and administered to five groups of 10 sheep, each animal receiving two intramuscular doses with a 21 days interval. Blood collection for serology by virusneutralization were performed until the $63^{\text {rd }}$ day after the first vaccination, two peaks in the curve of antibodies were observed, the first on day 14, ranged from 23.l to 138.6. The second peak was observed 14 days after the booster, and ranged from 301.3 to 1017.5 . In the $42^{\text {nd }}$ day after the booster, it was observed a titer variation from 82.4 to 305.9. The differences among antibody titers of each group of suggests a lower antigenicity of isolate ISO9898292 in comparison with the others, demonstrating a possible antigenic variation among the isolates. Thus, all isolates, with exception of ISO9898292, were immunogenic for the induction of neutralizing antibodies.
\end{abstract}

Key words: bovine herpesvirus 5, bovine menigoencephalitis, seroneutralization, vaccines.

\section{INTRODUÇÃO}

O herpesvírus bovino 5 (BoHV-5), ou vírus da encefalite bovina, é o agente etiológico da

\footnotetext{
'Laboratório de Infectologia Molecular Animal, Instituto de Biotecnologia Aplicada a Agropecuária (BIOAGRO), Universidade Federal de Viçosa (UFV), Viçosa, MG, Brasil. E-mail: marcia@ufv.br. *Autor para correspondência.

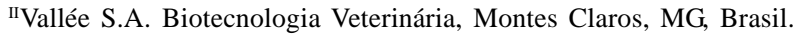

IIIDepartamento de Medicina Veterinária Preventiva, Universidade Federal de Santa Maria (UFSM), Santa Maria, RS, Brasil.

IVPlum Island Animal Disease Center, ARS, USDA, N.Y., U.S.A.
} 
meningoencefalite herpética bovina. A doença caracteriza-se histologicamente por meningoencefalite não-supurativa com necrose do córtex cerebral (ELIAS et al., 2004). O BoHV-5 pertence à família Herpesviridae, subfamília Alphaherpesvirinae, gênero Varicellovirus. Os membros da família Herpesviridae possuem um núcleo que contém DNA linear de cadeia dupla (dsDNA), uma cápside icosaédrica de aproximadamente 100 a 110nm de diâmetro, contendo 162 capsômeros. Os vírions apresentam material amorfo que envolve a cápside, denominado tegumento, e um envelope que contém glicoproteínas virais (MURPHY et al., 1999).

Infecções causadas pelo BoHV-5 já foram descritas em vários países da Europa, da América do Norte, da América do Sul, do Canadá e da Austrália. Nos países do Hemisfério Sul, há uma elevada incidência da doença (GEORGE, 1991). No Brasil, a meningoencefalite é freqüente no Rio Grande do Sul, Mato Grosso do Sul e Mato Grosso, com ocorrência de casos também nos Estados de São Paulo e Minas Gerais, conforme relatado por GOMES et al. (2002). Em todas as regiões, a doença ocorre principalmente na forma de surtos com morbidade variável, podendo atingir uma taxa de $25 \%$ e letalidade alta, alcançando uma taxa de até 100\% (SALVADOR et al., 1998).

Dentre as técnicas sorológicas mais utilizadas para a detecção de anticorpos contra o BoHV5 , podem-se destacar a soroneutralização, sendo esse o teste sorológico padrão, e o ensaio imuno-enzimático (RIET-CORREA et al., 1996).

O controle das infecções animais causadas pelo herpesvírus bovino 1 (BoHV-1) está baseado principalmente na imunização com vacinas inativadas ou vacinas vivas modificadas. As vacinas contra o BoHV-5 tendem a seguir as mesmas linhas das vacinas contra BoHV-1 (VAN OIRSCHOT et al., 1996).

Uma vez que os maiores índices de proteção observados entre animais imunizados são atribuídos possivelmente a um aumento no título de anticorpos, neste trabalho é avaliada a resposta antigênica em ovinos vacinados com diferentes isolados de BoHV-5. Dessa forma, será possível selecionar os isolados virais que induziram uma maior resposta antigênica como sendo futuros candidatos vacinais.

\section{MATERIAL E MÉTODOS}

Células e vírus. Células MDBK (Madin Darby bovine kidney) foram cultivadas em Meio Essencial Mínimo - MEM (GIBCO ${ }^{\circledR}$ ) estéril, acrescido de soro fetal bovino. Os cultivos foram mantidos incubados em estufa BOD a $37^{\circ} \mathrm{C}$, em sistema fechado. Os repiques celulares foram realizados a cada 72 horas utilizando-se tripsina a $37^{\circ} \mathrm{C}$ para descolamento da monocamada.

Foram utilizados seis isolados de BoHV-5, incluindo: SV163, SV507, 1807, EVI145, ISO9898292 e A509, sendo esse último utilizado apenas nos testes de soroneutralização. A origem de cada isolado é descrita na tabela 1. A propagação dos vírus foi realizada em três passagens em células MDBK, em uma multiplicidade de infecção (MOI) de 0,5. Após atingir 90\% de efeito citopático (ECP), os sobrenadantes dos cultivos foram recolhidos e clarificados por meio de centrifugação a $1590 \mathrm{xg}$ por 15 minutos a $4^{\circ} \mathrm{C}$ e armazenados em ultrafreezer a $-80^{\circ} \mathrm{C}$ até o momento do uso.

Para avaliar o comportamento replicativo das amostras virais em cultivo celular, foi realizada uma curva de crescimento viral de cada isolado. Células MDBK foram distribuídas em microplacas de 24 cavidades. As monocamadas celulares foram infectadas na MOI 0,5, utilizando cada isolado em duplicata. As placas foram incubadas em estufa de $\mathrm{CO}_{2}$ a $37^{\circ} \mathrm{C}$ e as coletas foram realizadas a cada quatro horas, durante 24 horas de cultivo. Durante as coletas, cada cavidade foi monitorada de acordo com o ECP na monocamada celular. As suspensões virais foram recolhidas após centrifugação a $1590 \mathrm{xg}$ por 15 minutos a $4^{\circ} \mathrm{C}$ e foram mantidas em ultrafreezer a $-80^{\circ} \mathrm{C}$ até serem tituladas por diluição limitante. Os títulos foram calculados de acordo com o método de doses infectantes para 50\% dos cultivos celulares (DICC $\mathrm{mL}_{50}^{-1}$ ), descrito por REED \& MUENCH(1938).

Formulação vacinal. Após a determinação do título viral de cada isolado, as suspensões virais foram diluídas, uniformizando todos os isolados com o mesmo título infeccioso. A suspensão viral constituiu de $40 \%$ do volume final da vacina. As suspensões virais foram inativadas com $3 \mathrm{mM}$ de etilenoimina binária (BEI). Após 24 horas de inativação, o BEI foi neutralizado com tiossulfato de sódio $2 \%$ v/v de BEI. O controle de vírus residual foi feito por meio da inoculação e observação da presença/ausência de efeito citopático em cultivos de células MDBK por três passagens sucessivas. Hidróxido de alumínio $\mathrm{Al}(\mathrm{OH})_{3}$ e saponina na quantidade de $20 \%$ e $0,06 \%$ do volume final, respectivamente, foram utilizadas como adjuvantes.

Experimentação animal. Foram utilizadas 55 ovelhas adultas, que foram escolhidas aleatoriamente nas vacinações e nas coletas de sangue. Os animais eram da raça Santa Inês. Eles foram divididos em cinco grupos, sendo 10 para cada vacina, e os cinco restantes foram utilizados como controles. O esquema de vacinação adotado consistiu de duas doses vacinais 
no dia 0 e 21, por via intramuscular. O volume da dose vacinal foi de $5 \mathrm{~mL}$ com título vacinal mantido em $10^{7,4}$ DICC $_{50}$ dose $^{-1}$.

Foram realizadas sete coletas de sangue nos dias zero, sete, $14,21,35,49,63$. O sangue foi coletado da veia jugular dos animais, e as coletas nos dias zero e 21 foram realizadas antes da vacinação. Após a coleta, as amostras de sangue foram mantidas em temperatura ambiente para coagulação. Após esse período, o soro de cada amostra foi coletado em microtubos e centrifugados a $1590 \mathrm{xg}$ por cinco minutos a $25^{\circ} \mathrm{C}$. As amostras de soro foram armazenadas em freezer a $-20^{\circ} \mathrm{C}$.

Sorologia. Os testes de soroneutralização (SN) foram realizados conforme descrito por HOUSE \& BAKER (1971), sendo adicionandos 200 DICC $_{50} /$ $50 \mu \mathrm{L}$ do isolado BoHV-5 A509 às diluições de soro de cada animal vacinado. Após a incubação da mistura soro-vírus por 12 horas a $37^{\circ} \mathrm{C}$ em estufa de $\mathrm{CO}_{2}$, foram adicionadas $50 \mu \mathrm{L}$ de suspensão de células MDBK na concentração de 300.000células $\mathrm{mL}^{-1}$. A leitura dos testes foi realizada após 96 horas de incubação, por meio do monitoramento do efeito citopático. Posteriormente aos testes de SN utilizando o isolado A509, foram realizados novos testes de SN para as amostras dos isolados BoHV-5 1807, SV507 e ISO9898292, utilizando o próprio isolado ISO9898292.

A resposta de anticorpos com atividade neutralizante anti-BoHV-5 de cada grupo de animais foi expressa em títulos médios geométricos (GMT), que foram analisados por análise de variância. As médias foram comparadas com o teste de Tukey, adotando o nível de 5\% de probabilidade.

\section{RESULTADOS E DISCUSSÃO}

Os resultados referentes às cinéticas de replicação dos diferentes isolados de BoHV-5 em cultivo celular estão apresentados na figura 1. Nota-se que, apesar de serem da mesma espécie, a replicação dos isolados apresenta cinética diferenciada em cultivo celular. Para o isolado BoHV-5 A509, houve uma variação significativa do título inicial após quatro horas de infecção, quando o título aumentou aproximadamente $1 \log$ DICC $_{50} \mathrm{~mL}^{-1}$ e após 12 horas houve variação de $1,5 \log$ DICC $_{50} \mathrm{~mL}^{-1}$ em relação ao título inicial, representados por picos na curva de replicação. Também foram detectadas variações do título infeccioso inicial acima de $1 \log$ DICC $_{50} \mathrm{~mL}^{-1}$ após quatro horas de infecção para os isolados SV507, EVI145, 1807 e SV163. O isolado SV507 não apresentou nenhum aumento significativo de título durante o ensaio, mantendo o título infeccioso próximo de 7log DICC $_{50} \mathrm{~mL}^{-1}$. Os isolados EVI145 e 1807 apresentaram uma variação significativa de 2,3 e 1,8log DICC $_{50} \mathrm{~mL}^{-1}$, respectivamente em relação ao título inicial após 12 horas de infecção. O isolado SV163 apresentou um aumento detectável do título infeccioso em relação ao título inicial com uma variação de 2,7log DICC $_{50} \mathrm{~mL}^{-1}$, após 24 horas. O isolado ISO9898292 apresentou, após oito horas de infecção, um aumento de $0,8 \log$ DICC $_{50}$ $\mathrm{mL}^{-1}$ em relação ao título inicial e, após 24 horas, a variação foi de $2,2 \log$ DICC $_{50} \mathrm{~mL}^{-1}$. O aumento diferenciado do título infeccioso entre os isolados observados nos diferentes tempos de coletas utilizadas sugere que cada isolado deve possuir um período de tempo distinto para concluir o ciclo de replicação.

Os anticorpos neutralizantes são componentes dos mecanismos de resposta imune do hospedeiro a hespevírus (NASH et al., 1993). Os resultados obtidos nos testes de SN mostraram serem eficazes em identificar os anticorpos específicos contra os isolados de BoHV-5. BRATANICH et al., (1991) também relataram a análise de anticorpos neutralizantes como ferramenta para o estudo da imunogenicidade dos BoHV-1 e BoHV-5.

O perfil da curva dos isolados mostrou dois picos referentes aos títulos de anticorpos alcançados pelos grupos. No entanto, o isolado ISO9898292 foi uma exceção a esse perfil, não apresentando dois picos notadamente distintos, em comparação com os demais isolados testados (Figura 2A). PETZHOLD et al. (2001), quando determinaram os títulos de anticorpos neutralizantes anti-BoHV-1 em bovinos vacinados com um único isolado de BoHV-1, também observaram dois picos de títulos de anticorpos, seguindo o esquema de vacinação e revacinação, respectivamente.

$\mathrm{Na}$ figura 2A, o primeiro pico foi demonstrado aos 14 dias após a vacinação, quando os títulos de anticorpos variaram entre 23,1, para o isolado SV507, e 138,6, para o isolado SV163. O segundo pico foi observado aos 14 dias após a revacinação, quando os títulos variaram entre 301,3, para o isolado EVI145, e 1017,5, para o isolado 1807. No 42ํ dia após a revacinação, foi observada uma variação no título entre 82,4 (EVI145) e 305,9 (1807). A diferença entre as médias de títulos de anticorpos de alguns grupos de animais sugere diferenças antigênicas, demonstrando uma possível variação entre os isolados. Diferenças antigênicas entre os BoHV-5 também foram encontradas por ALMEIDA et al. (1998), quando analisaram diferentes isolados por meio de ensaios com anticorpos monoclonais.

Na figura 2B, pode ser observado o perfil da curva apresentado pelo isolado ISO9898292, em que 


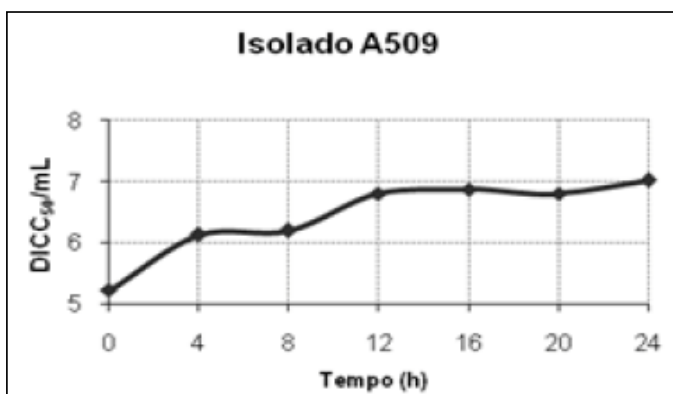

Isolado SV507

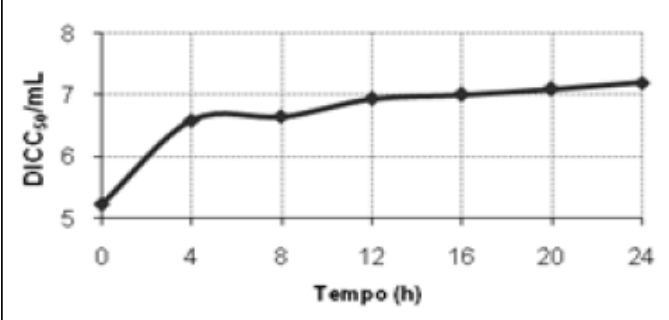

Isolado SV163

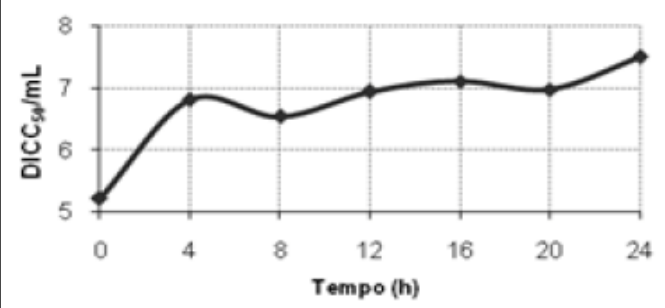

Isolado ISO9898292

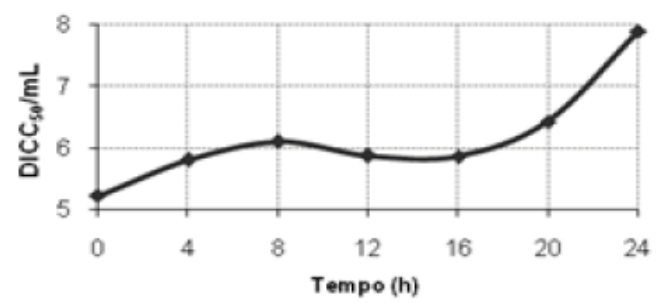

Isolado EVI145

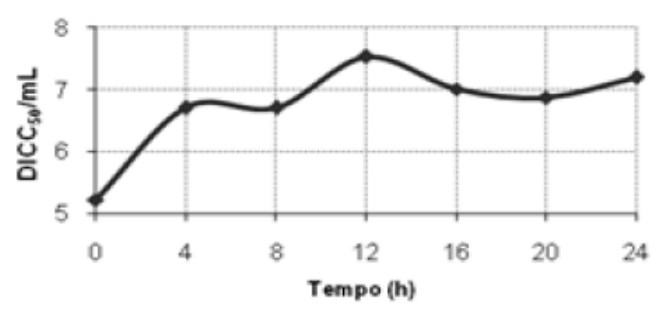

Isolado 1807

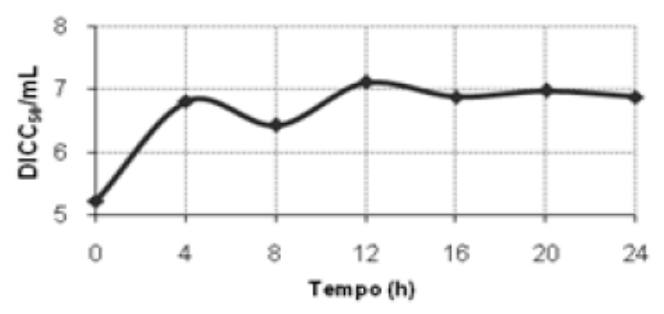

Figura 1 - Cinética de produção de partículas infecciosas de diferentes isolados de BoHV-5 (herpesvírus bovino 5) em cultura de células MDBK (Madin Darby bovine kidney).

não houve resposta antigênica significativa nos diferentes pontos de coleta de cada soro. O nãoreconhecimento dos anticorpos nos soros dos animais vacinados com os isolados BoHV-5 1807 e SV507 frente ao isolado ISO9898292, utilizado como antígeno no teste de SN, sugere a existência de diferenças antigênicas que podem ser causadas por possíveis variações nas glicoproteínas de superfície. Esaa hipótese corrobora os resultados demonstrados por D'ARCE et al, (2002), que, ao avaliarem diferentes isolados de BoHV-5 por ensaios de restrição enzimática e por testes de reconhecimento com anticorpos monoclonais, concluíram que os isolados também possuem características genômicas e antigênicas distintas.

Apesar da existência de anticorpos detectáveis para o próprio isolado ISO9898292, ficou comprovado que esse isolado possui baixa capacidade antigênica. Além disso, a curva de titulação de anticorpos para este isolado não seguiu o mesmo comportamento das demais, apresentando apenas um pico (Figura 2B), o que não é característico nas respostas imunes encontradas nos animais vacinados (ABBAS, 2005).

Para comparação das médias, foi adotado o Teste Tukey ao nível de significância de 5\% de probabilidade, e foram tomados como referência os picos da curva de anticorpos e o último dia de coleta a título de análise dos resultados. De acordo com a análise estatística realizada, os isolados de BoHV-5 1807, EVI145, SV163 e SV507 não diferiram estatisticamente entre si no $14^{\circ}$ dia após a primeira vacinação, que corresponde ao primeiro pico da curva. Já no 35o dia após a primeira vacinação, correspondente ao segundo

Ciência Rural, v.39, n.1, jan-fev, 2009. 


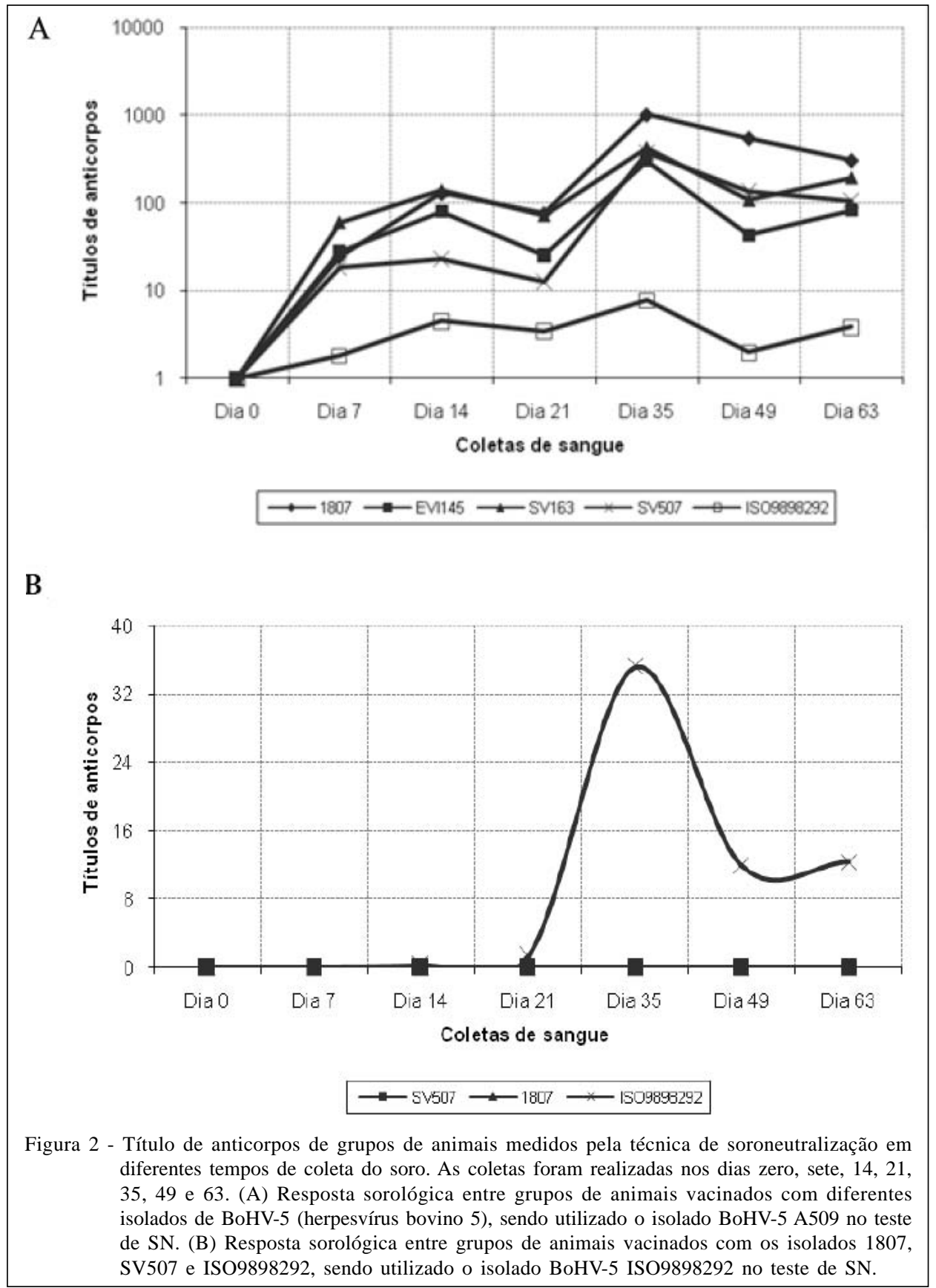

pico, houve diferença estatística significativa nos títulos de anticorpos entre os animais vacinados com os isolados de 1807, EVI145 e ISO9898292. No 63 dia, correspondente ao último ponto de coleta, os isolados de BoHV-5 1807, EVI145, SV163 e SV507 não diferiram estatisticamente entre si. Em todos os casos o isolado BoHV-5 ISO9898292 diferiu dos demais.

BELTRÃO et al. (2000) relataram que os maiores índices de proteção observados entre coelhos imunizados contra BoHV-1 podem ser atribuídos a possíveis diferenças antigênicas entre os isolados que compõem as vacinas. Segundo DESCÔTEAUX et al. (2003) os grupos de animais com maiores títulos de anticorpos anti-BoHV-1 estariam mais protegidos contra a infecção do que os grupos de animais que apresentavam baixos títulos de anticorpos. Seguindo esse raciocínio para o BoHV-5, os isolados 1807, EVI145, SV163 e SV507 são potenciais candidatos na produção de vacinas contra a meningoencefalite bovina. O isolado ISO9898292 não parece adequado para esse fim.

Ciência Rural, v.39, n.1, jan-fev, 2009. 
Este trabalho foi aprovado pelo Comitê de Ética e Biossegurança do Departamento de Veterinária/ Universidade Federal de Viçosa, e os estudos em animais foram realizados de acordo com as normas éticas cabíveis.

\section{REFERÊNCIAS}

ABBAS, A.K. et al. Imunologia celular e molecular. Livraria e Editora Revinter, 2005. 439p.

ALMEIDA, R.S. et al. Produção de anticorpos monoclonais contra o herpesvírus da encefalite bovina (BHV-5). Pesquisa Veterinária Gaúcha, v.4, p.65-70, 1998.

BELTRÃO, N. et al. Infecção e enfermidade neurológica pelo herpesvírus bovino tipo 5 (BHV-5): coelhos como modelo experimental. Pesquisa Veterinária Brasileira, v.20, n.4, p.144-150, 2000.

BRATANICH, A.C. et al. Comparative studies of BHV-1 variants by in vivo - in vitro tests. Journal of Veterinary Medicine Series B, v.38, p.41-48, 1991.

D’ARCE, R.C.F. et al. Restriction endonuclease and monoclonal antibody analysis of Brazilian isolates of bovine herpesviruses types 1 and 5. Veterinary Microbiology, v.88, p.315-324, 2002.

DESCÔTEAUX, L. et al. Comparison of humoral immune responses in dairy heifers vaccinated with 3 different commercial vaccines against bovine viral diarrhea virus and bovine herpevirus-1. Canadian Veterinary Journal, v.44, p.816821, 2003.

ELIAS, F. et al. Meningoencefalite e encefalomalacia por Herpsvírus bovino-5: distribuição das lesões no sistema nervoso central de bovinos naturalmente infectados. Pesquisa Veterinária Brasileira, v.24, n.3, p.123-131, 2004.
GEORGE, L.W. Understanding the encephalitis form of the infectious bovine rhinotracheitis. Food Animal Practice, p.335-337, 1991.

GOMES, L.I. et al. Detection of bovine herpesvirus type 5 $(\mathrm{BoHV}-5)$ in cattle in Southeast Brazil. Arquivo Brasileiro de Medicina Veterinária e Zootecnia, v.54, n.2, p.217220, 2002.

HOUSE, J.A.; BAKER, J.A. Bovine herpesvirus IBR-IPV. The antibody virus neutralization reaction. Cornell Veterinary, n.61, p.320-335, 1971.

MURPHY, F.A. et al. Veterinary virology. 3.ed. San Diego: Academic, 1999. 629p.

NASH, A. et al. The immune response to herpes simplex virus. Seminars in Virology, v.4, p.181-186, 1993.

PETZHOLD, S.A. et al. Neutralizing antibodies to bovine herpesviruses types 1 (BHV-1) and 5 (BHV-5) induced by an experimental, oil-adjuvanted, BHV-1 vaccine. Brazilian Journal of Veterinary Research and Animal Science,v.38, p.184-187, 2001.

REED, L.J.; MUENCH, H. A simple method of estimating $50 \%$ endpoints. American Journal Hygiene, v.27, p.493497, 1938.

RIET-CORREA, F. et al. Viroses confundíveis com febre aftosa. Ciência Rural, v.26, p.323-332, 1996.

SALVADOR, S.C. et al. Meningoencefalite em bovinos causada por herpesvírus bovino-5 no Mato Grosso do Sul e São Paulo. Pesquisa Veterinária Brasileira, v.18, p.75-82, 1998.

VAN OIRSCHOT, J.T. et al. Advances in the development and evaluation of bovine herpesvirus 1 vaccines. Veterinary Microbiology, v.53, n.1-2, p.43-54, 1996. 